\title{
Nonischemic Central Retinal Vein Occlusion in an Adolescent Patient with Ulcerative Colitis
}

\author{
Deepak Vayalambrone, ${ }^{1}$ Tsveta Ivanova, ${ }^{2}$ and Aseema Misra ${ }^{2}$ \\ ${ }^{1}$ Department of Ophthalmology, The Ipswich Hospital NHS Trust, Heath Road, Ipswich IP4 5PD, UK \\ ${ }^{2}$ Department of Ophthalmology, Norfolk and Norwich University Hospital NHS Foundation Trust, \\ Colney Lane, Norwich NR4 7UY, UK \\ Correspondence should be addressed to Deepak Vayalambrone, deepvayal@doctors.org.uk \\ Received 14 November 2011; Accepted 30 December 2011 \\ Academic Editor: N. Fuse
}

Copyright () 2011 Deepak Vayalambrone et al. This is an open access article distributed under the Creative Commons Attribution License, which permits unrestricted use, distribution, and reproduction in any medium, provided the original work is properly cited.

Inflammatory bowel disease (IBD) can present with extraintestinal manifestations occasionally involving the eye. Retinal vein occlusions are rarely seen and have never been reported in the pediatric population though vascular thrombosis can be associated with IBD. Here, we present a case of what we believe is the youngest reported patient with nonischemic central retinal vein occlusion (CRVO).

\section{Introduction}

Ulcerative colitis (UC) is an inflammatory bowel disorder (IBD) of unknown etiology with an incidence of 10.4/100,000 [1]. Ocular manifestations are known to be associated with IBD [2].

\section{Case Report}

A 16-year-old female patient presented to the emergency eye clinic with a 5-day history of blurred vision in her right eye. Her past ophthalmic history was unremarkable. Her past medical history was significant for a diagnosis of UC, 3 months previously, treated initially with oral prednisolone, at a dose of $60 \mathrm{mg}$ tapered down to $10 \mathrm{mg}$ when she was seen in the eye clinic. She was also on Azathioprine $100 \mathrm{mg}$ daily. She denied being on the oral contraceptive pill.

The visual acuity was $6 / 5$ in both eyes on checking with a Snellen's chart. There was no relative afferent pupillary defect, and colour vision testing using the Ishihara charts showed no abnormality, showing a clinically normal optic nerve function. Anterior segment examination revealed no abnormality, and the intraocular pressure was normal in both eyes. Fundus examination revealed dilated retinal veins, a few cotton wool spots, few deep retinal hemorrhages, peripapillary exudates, and mild oedema of the right optic disc (see Figure 1). Fundus examination of the left eye showed no abnormality. A diagnosis of a nonischemic central retinal vein occlusion was made. She had comprehensive range of blood tests including a full blood count, protein electrophoresis, lupus anticoagulant, autoantibodies, and thrombophilia screen all of which showed no abnormality. MRI scanning of the orbits and visual pathway showed no focal abnormality.

On followup at 3 months, she reported an improvement in the subjective visual symptoms. The visual acuity was $6 / 4$ in both eyes, and there was a marked reduction in the exudates. The cotton wool spots had disappeared. At her final followup 15 months after the initial presentation, all retinal signs had reversed and the visual acuity was $6 / 4$ in both eyes.

\section{Discussion}

Patients with IBD are known to develop ocular manifestations such as episcleritis, scleritis, neuroretinitis, central serous retinopathy, and orbital pseudotumours [2]. Vascular occlusions have also been reported, and IBD is thought to be associated with an increased risk of venous thrombosis [3]. We believe this to be the youngest patient with a nonischemic central retinal vein occlusion. CRVO has, however, been 


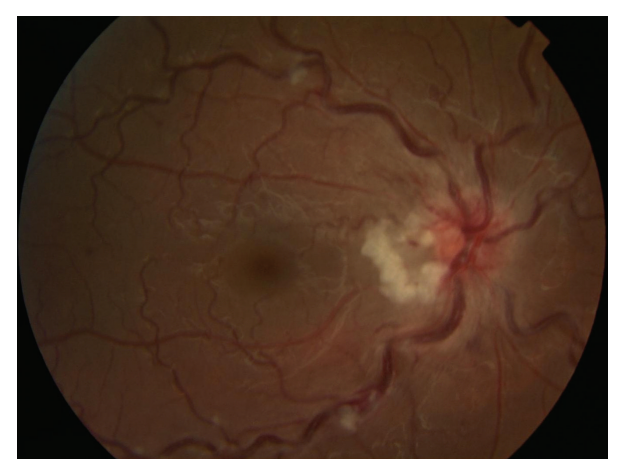

FIGURE 1: This is a picture of the fundus of the right eye showing dilatation of the veins, cotton wool spots (along the vessels), and exudates (adjacent to the optic disc).

reported in an otherwise healthy child [4]. Subclinical retinal vasculitis may be present in patients with IBD [5]. The risk of retinal venous occlusions may relate to the activity of the underlying systemic condition, and it is important for treating physicians to be aware of this complication at least during the active phase of IBD in young patients. The central Retinal vein occlusion study reported that $34 \%$ of patients with good perfusion (nonischemic) converted to ischemic within 3 years [6]. This conversion was most rapid in the first 4 months. The results of this and other studies need to be applied with caution in the pediatric age group as they were mainly conducted on an older population. The risk of ischemic CRVO in the pediatric population is unknown but is likely to be very low as a literature search revealed no reported cases.

\section{Conflict of Interests}

None of the authors have any financial conflict of interests with regards to the subject matter presented in this case report.

\section{References}

[1] S. Shivananda, J. Lennard-Jones, R. Logan et al., "Incidence of inflammatory bowel disease across Europe: is there a difference between north and south? Results of the European collaborative study on inflammatory bowel disease (EC-IBD)," Gut, vol. 39, no. 5, pp. 690-697, 1996.

[2] F. D. Ghanchi and B. J. Rembacken, "Inflammatory bowel disease and the eye," Survey of Ophthalmology, vol. 48, no. 6, pp. 663-676, 2003.

[3] W. Miehsler, W. Reinisch, E. Valic et al., "Is inflammatory bowel disease an independent and disease specific risk factor for thromboembolism?” Gut, vol. 53, no. 4, pp. 542-548, 2004.

[4] K. Lee, Y. R. Chung, and H. M. Lew, "Central retinal vein occlusion in an otherwise healthy child," Japanese Journal of Ophthalmology, vol. 52, no. 4, pp. 341-342, 2008.

[5] T. Matsuo and A. Yamaoka, "Retinal vasculitis revealed by fluorescein angiography in patients with inflammatory bowel disease," Japanese Journal of Ophthalmology, vol. 42, no. 5, pp. 398-400, 1998.
[6] J. C. Clarhson, "Natural history and clinical management of central retinal vein occlusion," Archives of Ophthalmology, vol. 115, no. 4, pp. 486-491, 1997. 


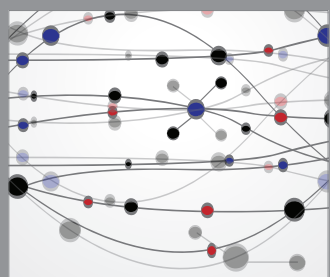

The Scientific World Journal
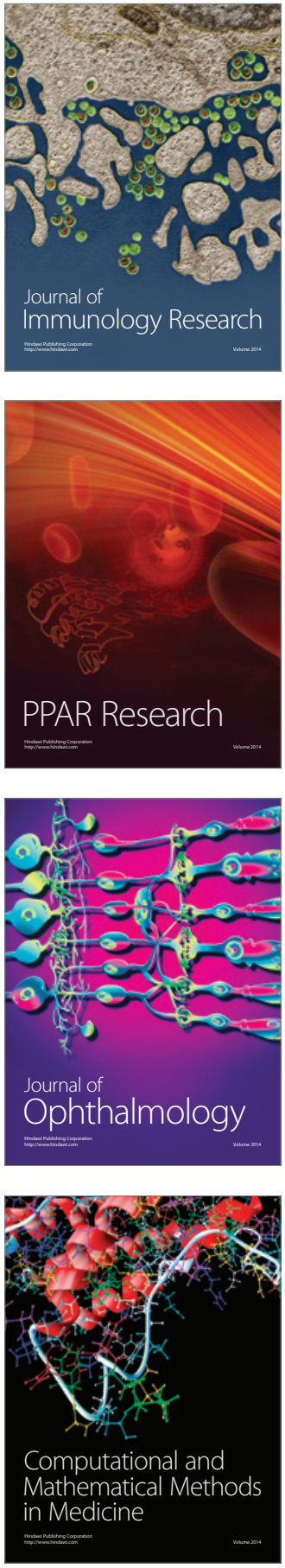

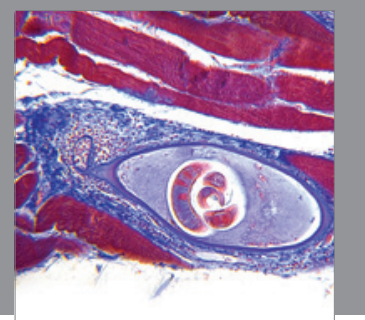

Gastroenterology

Research and Practice
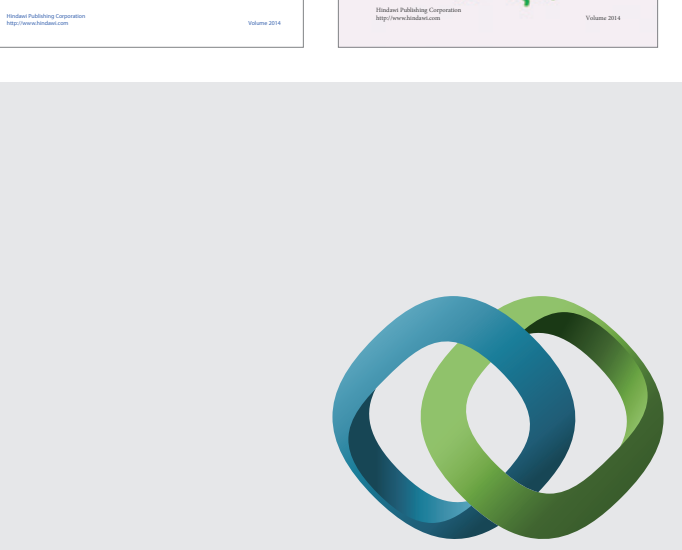

\section{Hindawi}

Submit your manuscripts at

http://www.hindawi.com
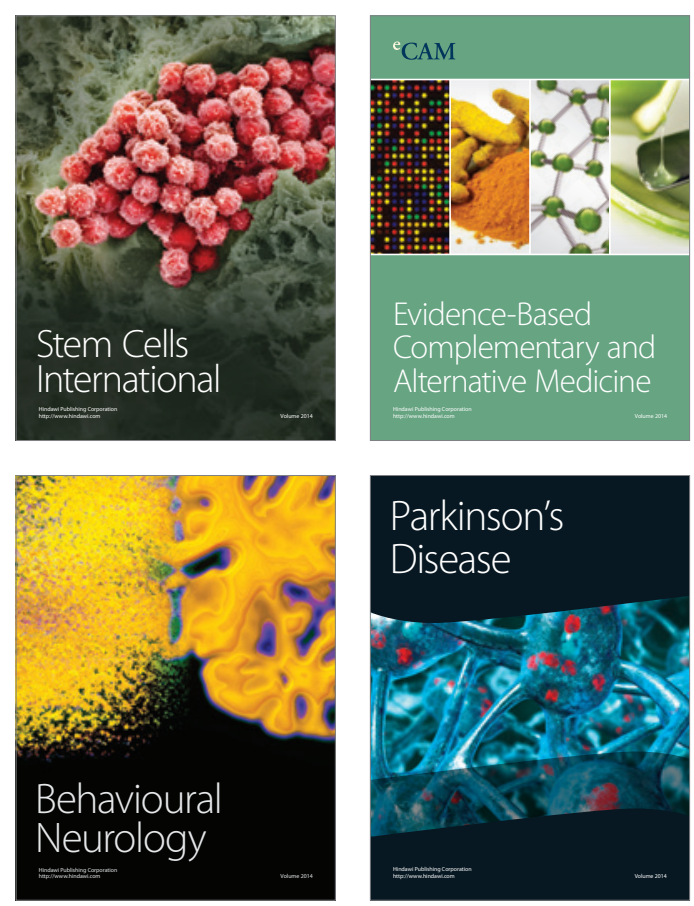

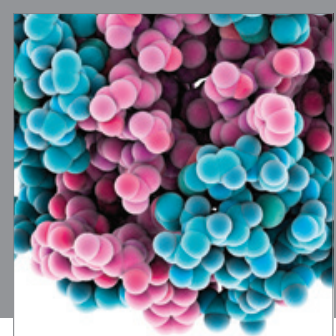

Journal of
Diabetes Research

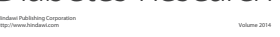

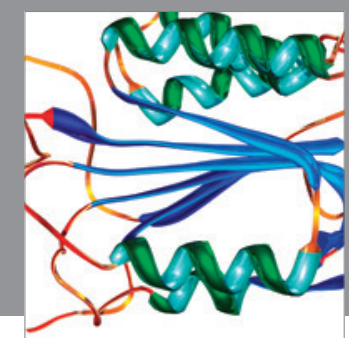

Disease Markers
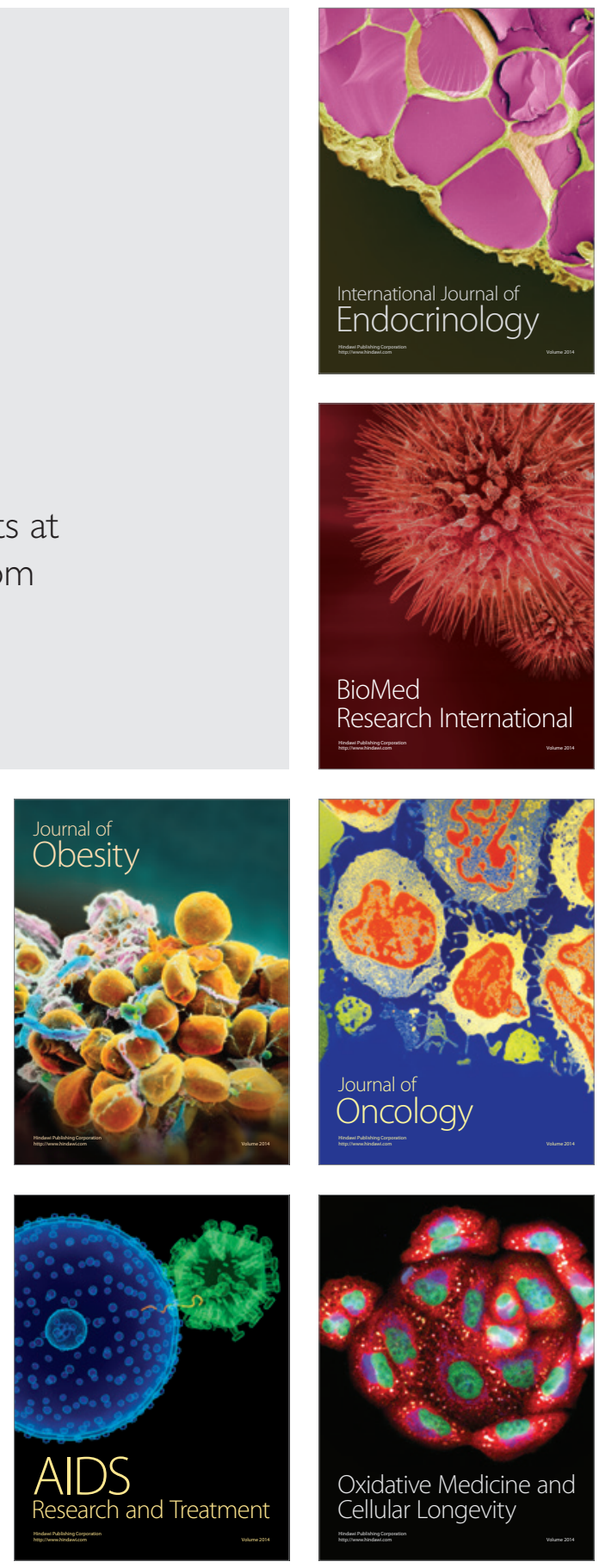